\title{
UV/Vis absorption spectroelectrochemistry of folic acid
}

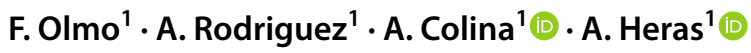

Received: 1 April 2021 / Revised: 9 July 2021 / Accepted: 9 August 2021 / Published online: 20 August 2021

(C) The Author(s) 2021

\begin{abstract}
$\mathrm{UV} / \mathrm{Vis}$ absorption spectroelectrochemistry is a very promising analytical technique due to the complementary information that is simultaneously obtained from electrochemistry and spectroscopy. In this work, this technique is used in a parallel configuration to study the oxidation of folic acid in alkaline medium. Herein, UV/Vis absorption spectroelectrochemistry has been used to detect both the oxidation products and the folic acid consumed at the electrode/solution interface, allowing us to develop an analytical protocol to quantify vitamin B9 in pharmaceutical tablets. Linear ranges of three orders of magnitude have been achieved in basic medium $(\mathrm{pH}=12.9)$, obtaining high repeatability and low detection limits. The spectroelectrochemical determination of folic acid in pharmaceutical tablets at alkaline $\mathrm{pH}$ values is particularly interesting because of the changes that occur in the optical signal during the electrochemical oxidation of FA, providing results with very good figures of merit and demonstrating the utility and versatility of this hyphenated technique, UV/Vis absorption spectroelectrochemistry.
\end{abstract}

Keywords Vitamin B9 $\cdot$ Pharmaceutical drug $\cdot$ Electrochemistry $\cdot$ UV/Vis absorption spectroscopy

\section{Introduction}

Instrumental analytical techniques commonly used to identify and quantify a specific molecule are typically based on the use of a single signal characteristic of the compounds under study. However, it is well-known that the use of two or more techniques can be much more helpful in the determination of a molecule. Techniques such as spectroelectrochemistry (SEC) are extremely useful analytical tools in the quantification of molecules and have proven to be very useful when dealing with complex samples or when there is a large matrix effect [1-5]. SEC encompasses a group of analytical techniques that are characterized by the simultaneous recording of electrochemical and spectroscopic signals

A. Colina

acolina@ubu.es

$\triangle$ A. Heras

maheras@ubu.es

F. Olmo

folmo@ubu.es

A. Rodriguez

andrearr@ubu.es

1 Department of Chemistry, Universidad de Burgos, Pza. Misael Bañuelos s/n, 09001 Burgos, Spain
[6-11]. Among all the SEC techniques, one of the most widely used is UV/Vis absorption SEC (UV/Vis-SEC), in which during the electrochemical oxidation or reduction of a molecule, changes in the molecular absorption spectrum of the studied analytes are observed due to the electrogeneration of the reaction products and/or the consumption of the native molecule [7-9, 12, 13].

SEC in general, and UV/Vis-SEC in particular, is a group of instrumental techniques commonly used in the characterization of new materials and/or molecules, in the study of electron transfer processes, or in the study of reaction mechanisms [6, 14-22]. However, the great potential of these multi-response techniques for quantitative analysis has not been enough explored [1, 2, 4, 5, 12, 23-26]. Among all SEC techniques, the coupling of electrochemistry and UV/Vis absorption spectroscopy is the most successful one in the field of electroanalysis. Significant improvements in instrumentation and SEC devices, such as SEC cells, have significantly contributed to the fruitful use of these operando and multi-response techniques for analytical purposes $[1,9,10,15,27-29]$. From a quantitative point of view, it should be remarked that UV/Vis-SEC can provide a dual determination of the analyte studied, using both the electrochemical and the spectroscopic signals, providing much more reliable and fully validated results. In some cases, the 
electrochemical signal is not good enough for quantitative purposes, but a good optical signal is obtained during the electrochemical process. Furthermore, UV/Vis-SEC results are characterized by a high reproducibility and very low relative standard deviation values (RSD), parameters required by all analytical techniques used for quantitative purposes. Lastly, it should be pointed out that the information gathered in this type of experiments, concerning the reaction mechanism involved in the electron transfer process studied, helps significantly not only to detect outliers but also to obtain an explanation for why that point is an outlier [28].

Vitamin B9 belongs to the group of water-soluble vitamins, and its structure is derived from folic acid (FA). FA is a cofactor in methylation reactions, in biochemical reactions related to the synthesis of some nitrogen bases, such as adenine, guanine, or thymine, and in amino acid metabolism. Therefore, deficiency of this vitamin is directly related to improper DNA replication and, consequently, to improper cell division. Increased metabolic demand for folate is common in pregnancy due to megaloblastic anemia. A deficiency of this vitamin in pregnancy can lead to defects in the embryo, especially in the neural tube. Deficiency of vitamins B9 and B12 is also associated with some diseases related to the central nervous system such as dementia, depression, or Alzheimer's disease and with vascular diseases such as thrombosis [30-33]. To avoid FA deficits, since the human body is not able to produce FA, adequate levels of vitamin B9 must be achieved through diet or food supplements.

FA derives from three chemical structures: a 6-methylpterin, $p$-aminobenzoic acid, and glutamic acid [30]. There are many different folates depending on the glutamate residues included in the chemical structure [32]. On the other hand, folate exits in different oxidation states. The natural folates have the pterin ring in its reduced state such as 7,8-dihydrofolate or 5,6,7,8tetrahydrofolate, not being a natural physiological form of this vitamin the pterin ring in its high oxidized state [30, 32, 34].

The solubility of FA in water is low in neutral medium $\left(1.6 \mathrm{mg} / \mathrm{L}\right.$ at $\left.25^{\circ} \mathrm{C}\right)$ and depends strongly on the $\mathrm{pH}$ of the solution [35]. Under high acidic conditions, the solubility of FA increases significantly, but its stability decreases at $\mathrm{pH}$ values below 5. On the other hand, solubility increases significantly with increasing $\mathrm{pH}(50 \mathrm{mg} / \mathrm{mL}$ at $1 \mathrm{M} \mathrm{NaOH})$, being stable solutions when protected from light [30].

In alkaline medium, it presents three well-defined absorption bands in the UV-Vis region, at 256, 283, and $365 \mathrm{~nm}$ assigned to the $\pi-\pi^{*}$ electronic transitions due to the pterin ring and $p$-aminobenzoic acid moieties of FA [36-38], and its electrochemical properties, both in oxidation and reduction processes, are related to the conjugated pteridine ring $[39,40]$.

FA has been studied and quantified with different analytical techniques such as photoluminescence [41-43], UV/ Vis absorption spectroscopy [44, 45], electrochemistry [39,
46-49], HPLC [50, 51], or HPLC-MS [52, 53]. Some of these techniques require complex and long sample pretreatments; others imply the modification of the surface used to determine this molecule such as in electrochemistry. Since FA has a characteristic UV/Vis absorption spectrum and its oxidation process is previously described, UV/Vis-SEC can be a suitable instrumental technique to study the electron transfer reaction of vitamin B9.

In this work, a UV/Vis-SEC-based methodology is proposed to quantify FA in a pharmaceutical drug. Specifically, in this work, FA is electrochemically oxidized, while changes in the UV/Vis absorption spectra, which are used to identify and quantify FA, are simultaneously recorded. The determination protocol developed is simple and not timeconsuming and provides optimal results in the identification and quantification of FA. By adapting this protocol to other substances and other matrices, this approach can be used for the analysis of other drugs in real samples.

\section{Experimental}

\section{Chemicals and materials}

FA (97\%, Sigma-Aldrich), KCl (99+\%, ACROS Organics), $\mathrm{NaOH}$ (ACROS Organics), glacial acetic acid (VWR), and sodium acetate ( $>99 \%$, VWR) were of analytical grade and were used as delivered without further purification. Yodocefol ${ }^{\circledR}$ (ItalFarmaco). The protocols used in all the experiments performed in this work ensure safe and careful handling of all reagents.

All solutions were freshly prepared using ultrapure deionized water $\left(18.2 \mathrm{M} \Omega \mathrm{cm}\right.$ resistivity at $25^{\circ} \mathrm{C}$, Milli-Q Direct 8 , Millipore).

\section{Instrumentation}

UV/Vis-SEC measurements were performed using a customized UV-VIS SPELEC instrument (Metrohm-DropSens), employing the experimental setup described previously [1, 5]. A deuterium lamp was used because the reagents and products of this electrochemical process absorb electromagnetic radiation in the UV region. Carbon DRP-110 screenprinted electrodes (SPE, Metrohm-Dropsens) were used for UV/Vis-SEC measurements. These C-SPEs consist of a carbon working electrode (C-WE) of $4 \mathrm{~mm}$ diameter, a silver pseudo-reference electrode, and a carbon counter electrode.

UV/Vis-SEC experiments in normal configuration were carried out using the Teflon ${ }^{\circledR}$ SEC cell for reflection experiments (DRP-REFLECELL, Metrohm-DropSens) and a reflection probe (DRP-RPROBE, Metrohm-DropSens). 
UV/Vis-SEC experiments in parallel configuration were carried out by facing and attaching two $100-\mu \mathrm{m}$-bare optical fibers (Avantes) to the surface of the C-WE of the SPEs that were placed at the boxed connector for SPEs (DSC, Metrohm-DropSens). The optical pathway was measured for each C-SPE used, which is in all cases between 2 and $3 \mathrm{~mm}$ in length. A $50-\mu \mathrm{L}$ aliquot of the solution studied is used in each experiment.

\section{UV/Vis-SEC study of the effect of $\mathrm{pH}$ on FA oxidation}

$0.1 \mathrm{M}$ acetic/acetate buffer solutions were prepared, being their $\mathrm{pH}=5.0 .1 \mathrm{M} \mathrm{KCl}$ solutions were prepared, being their $\mathrm{pH}=7$. Also, $0.1 \mathrm{M} \mathrm{NaOH}$ solutions were prepared, being their $\mathrm{pH}=12.9$.

UV/Vis-SEC experiments in normal configuration were performed to test the influence of the $\mathrm{pH}$ on the process of electrochemical oxidation of FA. Solutions of $100 \mu \mathrm{M}$ FA in the specific medium tested (buffer acetic/acetate, $\mathrm{KCl}$ or $\mathrm{NaOH}$ ) were prepared, and cyclic voltammetry experiments were carried out. The potential was scanned in the anodic direction at $0.01 \mathrm{~V} \mathrm{~s}^{-1}$ between 0.00 and $+0.90 \mathrm{~V}(0.1 \mathrm{M}$ $\mathrm{NaOH})$ or between +0.70 and $+1.30 \mathrm{~V}(0.1 \mathrm{M}$ acetic/acetate buffer and $0.1 \mathrm{M} \mathrm{KCl}$ ), and simultaneously the evolution of the absorbance between 240 and $900 \mathrm{~nm}$ is recorded along the whole experiments. The spectrum of the sample at the starting potential was taken as reference, and changes of absorbance respect to this reference spectrum $(\Delta \mathrm{A})$ were recorded. The integration time for absorptiometric data in all experiments was $400 \mathrm{~ms}$.

\section{UV/Vis-SEC quantification protocol}

UV/Vis-SEC measurements were performed in $0.1 \mathrm{M} \mathrm{NaOH}$ $(\mathrm{pH}=12.9)$, changing the concentration of FA between 5 and $100 \mu \mathrm{M}$. SEC experiments were performed collecting the evolution of absorption spectra between 240 and $900 \mathrm{~nm}$ during a cyclic voltammetry experiment. The potential was scanned between 0 and $+0.90 \mathrm{~V}$ at $0.02 \mathrm{~V} \mathrm{~s}^{-1}$, starting all the experiments in the anodic direction. In all UV/Vis-SEC experiments, the first spectrum of the sample at $0 \mathrm{~V}$ was taken as reference, and therefore, the change of absorbance respect to the reference spectrum was recorded, expressed as $\Delta A$ in all figures. Time-resolved UV/Vis-SEC measurements were performed using an integration time of $400 \mathrm{~ms}$.

The calibration models were constructed by randomly measuring the different FA solutions, varying its concentration between 5 and $100 \mu \mathrm{M}$. Each point in the calibration models was replicated three times. Before performing the spectroelectrochemical measurements, the SPEs were pretreated by placing $50 \mu \mathrm{L}$ of a $0.1 \mathrm{M} \mathrm{NaOH}$ solution and performing 10 potential scans between 0 and $+0.90 \mathrm{~V}$ at $0.02 \mathrm{~V} \mathrm{~s}^{-1}$. The same C-SPE was used for each calibration test. The blank solution containing $0.1 \mathrm{M} \mathrm{NaOH}$ was measured before and after sampling all the calibration samples to check that the WE does not undergo any modification.

\section{Test sample preparation}

Yodocefol ${ }^{\circledR}$ tablets were used as test sample. Each tablet of this pharmaceutical drug contains $400 \mu \mathrm{g}$ of FA, $262 \mu \mathrm{g}$ of potassium iodide, $2 \mu \mathrm{g}$ of vitamin B12, and different excipients (110 mesh lactose monohydrate, microcrystalline cellulose, sodium potato starch glycolate, calcium stearate, trisodium citrate, citric acid, and maltodextrins). To prepare test samples of this drug, first a dispersion of the tablet is prepared in $25 \mathrm{~mL}$ of $0.1 \mathrm{M} \mathrm{NaOH}$. After decantation of the non-water-soluble excipients, 1-mL aliquots of the supernatant were centrifuged at $4000 \mathrm{rpm}$ for $28 \mathrm{~min}$ in Eppendorf vials. The supernatant obtained was directly used as drug sample to be quantified that considering the starting dilution, the FA concentration in this test sample was $36 \mu \mathrm{M}$.

\section{Data acquisition and analysis software}

SPELEC instrument was controlled by DropView SPELEC software (Metrohm-DropSens), performing operando, timeresolved SEC experiments with fully synchronized data acquisition.

Matlab 2018 and R 3.6.1 were used to analyze all UV/VisSEC experiments, to generate the calibration models, and to predict the FA concentration of test samples.

\section{Results and discussion}

\section{FA oxidation with UV/Vis absorption spectroelectrochemistry}

UV/Vis-SEC can be performed using a normal or parallel arrangement. When soluble products of reaction are formed during the electrochemical process, UV/Vis in parallel arrangement is more suitable for quantitative purpose. Nevertheless, UV/Vis-SEC in normal arrangement is very suitable for performing a rapid screening of the best experimental conditions used for quantification. Thus, UV/VisSEC in normal arrangement was used to look for the best electrolytic medium to obtain a sensitive and reproducible optical response.

Three different electrolytic media were explored to determine FA using UV/Vis-SEC in normal configuration: (a) $0.1 \mathrm{M} \mathrm{NaOH}(\mathrm{pH}=12.9)$, (b) $0.1 \mathrm{M} \mathrm{KCl}(\mathrm{pH}=7)$, and (c) $0.1 \mathrm{M}$ acetic/acetate buffer $(\mathrm{pH}=5)$. Figure 1 shows the contour plots for the three different electrolytic media tested, where evolution of absorption spectra during a UV/Vis-SEC experiment was shown. As can be observed, only in alkaline 
Fig. 1 Contour plots of the absorbance with time/potential during SEC experiments in a $100 \mu \mathrm{M}$ FA solutions in (a) $0.1 \mathrm{M} \mathrm{NaOH}(\mathrm{pH}=12.9)$, (b) $0.1 \mathrm{M} \mathrm{KCl}(\mathrm{pH}=7)$, and (c) $0.1 \mathrm{M}$ acetic/acetate buffer $(\mathrm{pH}=5)$. Potential was scanned between 0.00 and $+0.90 \mathrm{~V}$ at $0.01 \mathrm{~V} \mathrm{~s}^{-1}$ in $(\mathbf{a})$, between $+0.70 \mathrm{~V}$ and $+1.30 \mathrm{~V}$ at $0.01 \mathrm{~V} \mathrm{~s}^{-1}$ in $(\mathbf{b})$, and between $+0.70 \mathrm{~V}$ and $+1.30 \mathrm{~V}$ at $0.01 \mathrm{~V} \mathrm{~s}^{-1}$ in $(\mathbf{c}) . \Delta \mathrm{A}$ values in normal configuration were measured taking the starting FA solution as reference spectrum. Integration time was $400 \mathrm{~ms}$
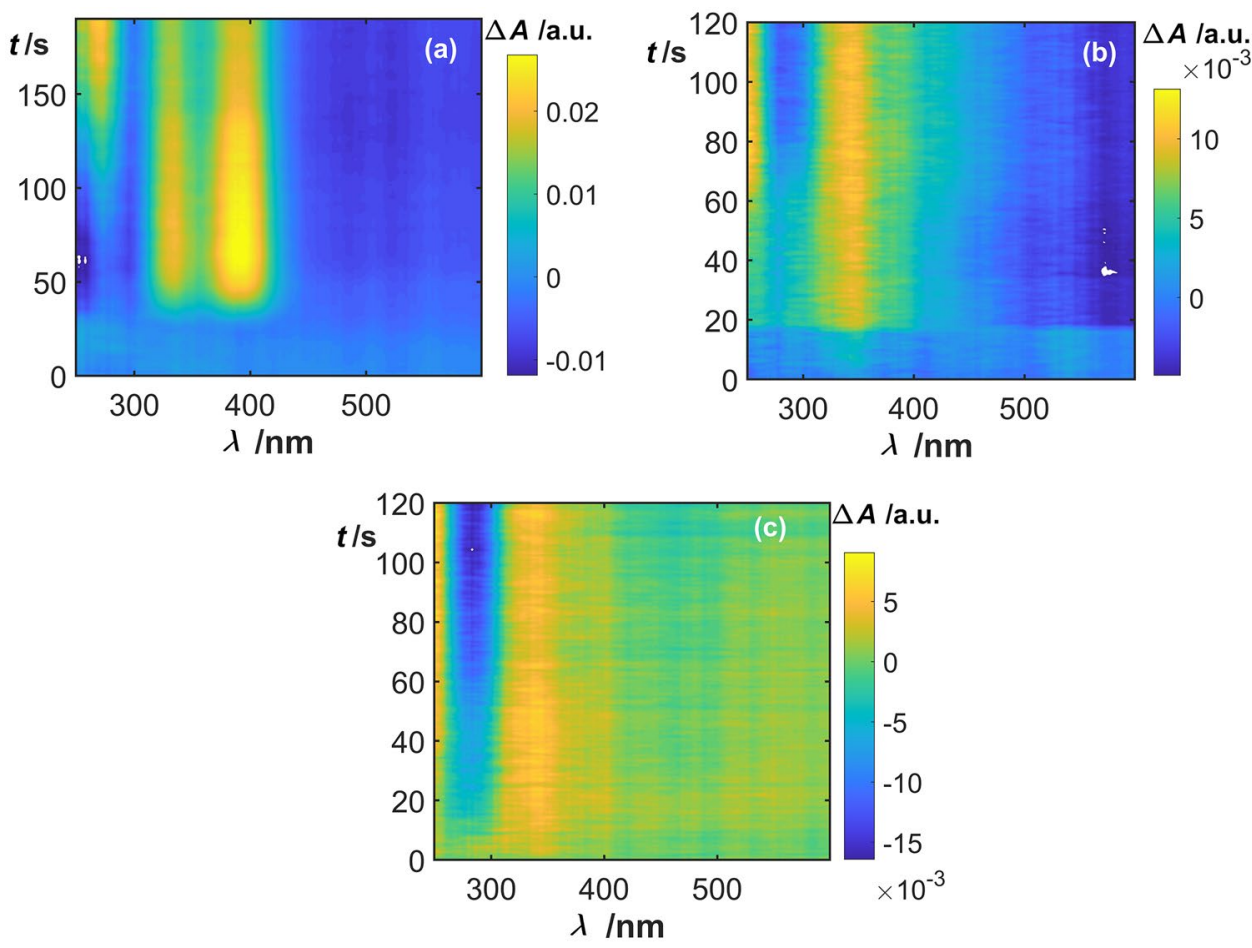

media, well-defined and sufficiently intense UV/Vis absorption signals with suitable spectral resolution were recorded.

Figure 2 shows the SEC responses obtained in parallel configuration with a $100 \mu \mathrm{M}$ FA and $0.1 \mathrm{M} \mathrm{NaOH}$ solution ( $\mathrm{pH}=12.9)$. As can be seen, a small and ill-defined anodic peak can be observed in the cyclic voltammogram between +0.50 and $+0.60 \mathrm{~V}$ (CV, Fig. 2a). This ill-defined anodic peak must be related to the oxidation of FA since it
Fig. 2 (a) $\mathrm{CV}$ of the blank solution $(0.1 \mathrm{M} \mathrm{NaOH}$, blue line) and of the FA solution (orange line). (b) Absorption spectra recorded at different potentials during the anodic scan, and (c) CVAs at 260 (blue line), 295 (orange line), 332 (yellow line), and 392 (violet line) $\mathrm{nm}$ in a $100 \mu \mathrm{M} F A$ and $0.1 \mathrm{M} \mathrm{NaOH}$ solution. Potential was scanned between $0.00 \mathrm{~V}$ and $+0.90 \mathrm{~V}$ at $0.02 \mathrm{~V} / \mathrm{s} . \Delta \mathrm{A}$ values in parallel configuration were measured taking the starting FA solution at $0.00 \mathrm{~V}$ as reference spectrum. Integration time for absorbance measurements was $400 \mathrm{~ms}$.

Optical path length $=2.3 \mathrm{~mm}$
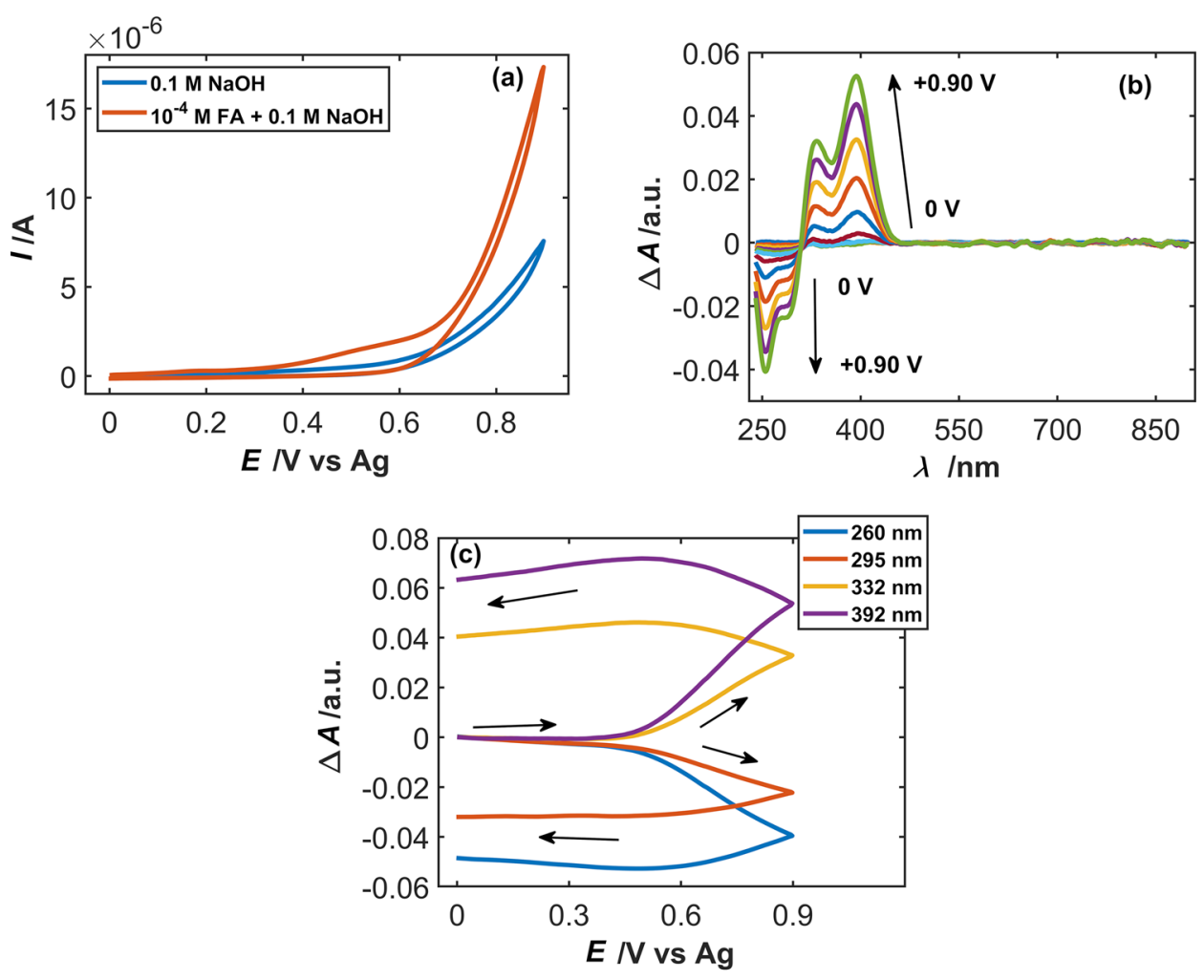
is the main difference with respect to the $\mathrm{CV}$ of the blank solution. However, a clear evolution of the UV/Vis absorption spectra is appreciated during the CV (Fig. 2b). These absorbance changes are related to the oxidation of FA as can be clearly observed in the cyclic voltabsorptograms (CVA, Fig. 2c).

In the evolution of the spectra during the anodic scan (Fig. 2b), four absorption bands were observed, two overlapped positive ones at 332 and $392 \mathrm{~nm}$ and two small overlapped negative ones at 260 and $295 \mathrm{~nm}$, showing a single isosbestic point at $312 \mathrm{~nm}$. This isosbestic point indicates that there is an interconversion of the reactant to a single product that absorbs electromagnetic radiation in this spectral range. Negative absorbance values are observed because the reference spectrum is taken in the FA initial solution. At alkaline $\mathrm{pH}$ values, FA is found as folate anion [54], showing three bands around 256, 285, and $365 \mathrm{~nm}$ according to literature $[36,37,44,55,56]$. According to the literature [38], the absorption band decreasing at $260 \mathrm{~nm}$ is related to the $\pi-\pi^{*}$ transition of the pterin moiety, while the absorption band at $295 \mathrm{~nm}$ is related to the $\pi-\pi^{*}$ transition of the aminobenzoyl ring. Thus, the two absorption bands with positive values can be ascribed to the formation of a new compound during the oxidation of FA, while the two absorption bands with negative values correspond to the FA that is consumed from the solution adjacent to the C-WE during the oxidation process. CVA at these four absorption bands (Fig. 2c) has shown how the oxidation of FA begins at $+0.55 \mathrm{~V}$, since the absorbance increases in the bands associated with the oxidation product of FA and decreases in the bands associated with the consumption of FA. Once the vertex potential $(+0.90 \mathrm{~V})$ has been reached, absorbance continues increasing in the cathodic scan until it reaches a maximum value around $+0.60 \mathrm{~V}$. From this potential downwards, the absorbance only decreases slightly during the cathodic scan because of the diffusion of the products of the electrochemical process.

As was described in bibliography, FA oxidation reaction is irreversible, since FA is oxidized to an enamine that subsequently suffers a hydrolysis process, breaking this enamine into the pterin moiety as 6-formylpterin and the $p$-aminobenzoylL-glutamic acid (PGA) [37, 46]. After oxidation, absorption spectral changes $(\Delta \mathrm{A})$ at wavelengths longer than $300 \mathrm{~nm}$ should correspond to the 6-formylpterin fragment. This hydrolysis of FA in alkaline medium has been previously reported [40], and according to the literature, the $\Delta \mathrm{A}$ spectra of derivatives of the 6-formylpterin fragment have shown absorption bands between 300 and $400 \mathrm{~nm}[55,57,58]$. In our case, we observe absorption bands at 332 and $392 \mathrm{~nm}$, which confirm this hydrolysis process.

From the electrochemical signal, it is not easy to follow the oxidation of FA due to the ill-defined anodic peak recorded; however, the optical signal clearly confirms that the molecule is oxidized in this alkaline electrolytic medium. This is one of the main advantages of UV/Vis-SEC because the electrochemical oxidation process of molecules can be studied without a clear evidence of the process in the electrical signal.

\section{FA determination with UV/Vis absorption spectroelectrochemistry}

Once the optimal conditions for the study of FA were determined, the calibration of FA using the optical signal was performed. In this case, the electrochemical signal cannot be used as no oxidation peak is observed. Different tests and preliminary experiments were carried out to determine the linear range. At concentrations greater than $100 \mu \mathrm{M}$, no linear relationship between concentration and absorbance was found. On the other side, concentration values below $5 \mu \mathrm{M}$ cannot be easily differentiated from the signal noise. Thus, a calibration set of known FA concentration samples between 5 and $100 \mu \mathrm{M}$ was prepared, with standards of $5,8,10,20,40,60$, 80 , and $100 \mu \mathrm{M}$ of $\mathrm{FA}$, always in $0.1 \mathrm{M} \mathrm{NaOH}$ to ensure that the desired $\mathrm{pH}$ is the same in all solutions $(\mathrm{pH}=12.9 \pm 0.1)$. A parallel configuration UV/Vis-SEC cell was selected for the measurements because it is more sensitive than normal arrangement for soluble products of the electrochemical reaction due to its longer optical path length.

Figure 3 shows the optical responses obtained during the calibration procedure for some of the tested samples: 0,8 , 40,80 , and $100 \mu \mathrm{M}$. Figure $3 \mathrm{a}$ shows the UV/Vis absorption spectra of these FA samples recorded at $+0.55 \mathrm{~V}$ in the reverse scan, in the spectral range of 200-500 $\mathrm{nm}$ where absorbance changes are detected. As was expected, the higher the FA concentration, the higher the recorded absorbance related to the oxidation/hydrolysis products. A good reproducibility between measurements was obtained as can be deduced from the two samples shown at $40 \mu \mathrm{M}$, which practically are overlapped. The CVAs at $392 \mathrm{~nm}$ for the solutions of concentration equal to those shown in Fig. 3a are shown in Fig. 3b. This wavelength is selected because it corresponds to the most sensitive absorption band. Oxidation starts from a potential of $+0.55 \mathrm{~V}$ onwards, observing an increase of absorbance, reaching a maximum during the reverse scan at $+0.55 \mathrm{~V}$.

Figure 4 shows the calibration curves obtained for the concentration range of 5 to $100 \mu \mathrm{M}$ using the bands at $332 \mathrm{~nm}$ and $392 \mathrm{~nm}$, the two positive absorption bands shown in Fig. 2b and Fig. 3a. Figures of merit of the two calibrations are summarized in Table 1.

The calibration model at $392 \mathrm{~nm}$ is more sensitive than the one at $332 \mathrm{~nm}$ as deduced from the slope. Very good and similar coefficients of determination $\left(R^{2}\right)$ were obtained for the two calibrations models, which provide similar limits of detection in the two cases. The low values of the standard deviation of residuals $\left(S_{\mathrm{yx}}\right)$ indicate 
Fig. 3 (a) Absorption spectra at $+0.55 \mathrm{~V}$ obtained during the reverse scan recorded at different concentrations. (b) CVAs at $392 \mathrm{~nm}$ obtained at different concentrations. Experimental conditions in the Fig. 2 caption
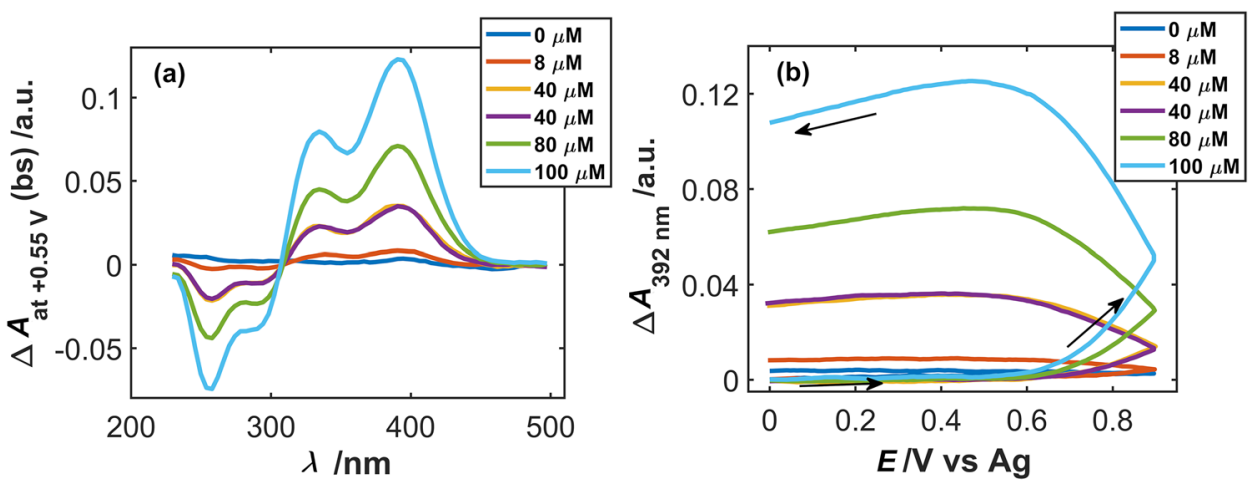

the low dispersion of data, as can be observed in Fig. 4 for the three replicates of each point, where the error bars are very small. The limits of detection (LOD) are very similar with the two wavelengths.

Repeatability of the UV/Vis-SEC method was evaluated by constructing three regression models for each wavelength (332 and $392 \mathrm{~nm}$ ) under the same experimental conditions described above and evaluating the repeatability of the slopes. For the calibrations at 332 and $392 \mathrm{~nm}$, a \%RSD of 4.36 and 2.20 was obtained, respectively. From these values, we can conclude that the UV/Vis-SEC method has a very good repeatability in the quantification of FA in alkaline medium.

\section{FA determination in a pharmaceutical tablet}

Once demonstrated that this UV/Vis-SEC method is reliable, repeatable, and sensitive, the determination of FA in a drug (Yodocefol ${ }^{\circledR}$ ) was performed, probing the capability of the method for real samples. Yodocefol ${ }^{\circledR}$ tablet contains $262 \mu \mathrm{g}$

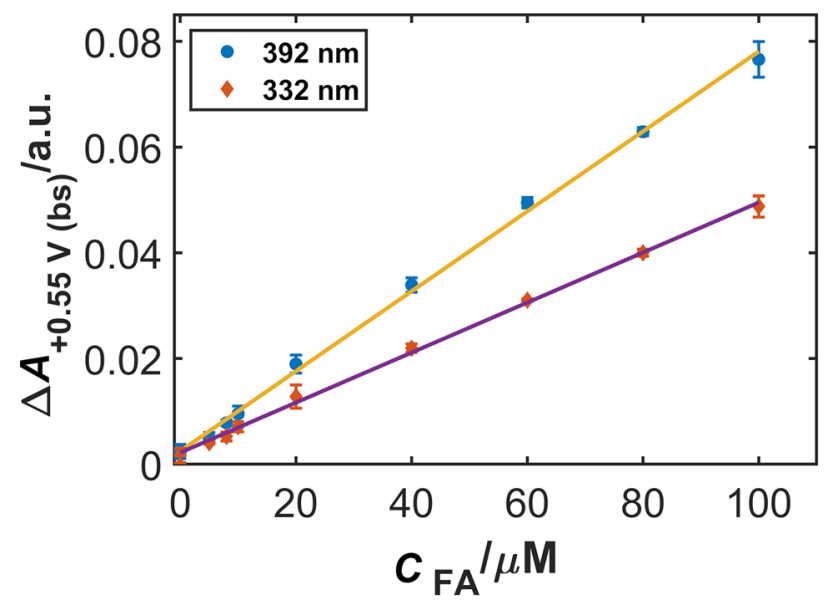

Fig. 4 Calibration curves of FA obtained from the CVAs at $+0.55 \mathrm{~V}$ in the reverse scan at 332 (violet line) band $392 \mathrm{~nm}$ (yellow line). Experimental conditions in the caption of Fig. 2. Each point was replicated three times. Optical path length $=2.3 \mathrm{~mm}$ of KI (equivalent to $200 \mu \mathrm{g}$ of $\mathrm{I}_{2}$ ), $400 \mu \mathrm{g}$ of FA, and $2 \mu \mathrm{g}$ of vitamin B12 and different excipients. Therefore, the analyte is accompanied with potential interfering compounds. The drug sample was prepared as described in the experimental section.

A new calibration procedure was performed to carry out the determination of a tablet of Yodocefol ${ }^{\circledR}$ using the UV/ Vis-SEC method described above. Since the tablets are dissolved in $25 \mathrm{~mL}$ of $0.1 \mathrm{M} \mathrm{NaOH}$ solution, and they contain $400 \mu \mathrm{g}$ of FA, the real concentration of the test sample was $36 \mu \mathrm{M}$ of FA.

Figure 5a shows the UV/Vis absorption spectra registered during the oxidation of the Yodocefol ${ }^{\circledR}$ sample prepared in alkaline medium. Only the four bands that had been observed for the FA standard solutions are detected, although they are slightly noisy due to scattering of light, possibly caused by the presence of small particles of the excipient that have not been completely removed during the centrifugation process. It is noteworthy the robustness of the method, allowing us to perform the determination of the analyte despite the dispersion produced by this complex matrix. Figures of merit for the new calibration models at 332 and $392 \mathrm{~nm}$ are very similar to the ones obtained in the calibration shown in Table 1. In this case, the slope is higher $\left(8.1 \cdot 10^{-4} \mu \mathrm{M}^{-1}\right.$ at $332 \mathrm{~nm}$ and $13.4 \cdot 10^{-4} \mu \mathrm{M}^{-1}$ at $392 \mathrm{~nm}$ ) because the optical pathway is longer $(2.90 \mathrm{~mm})$. Two replicated experiments are shown in Fig. 5. As can be seen, the two signals (spectra, inset Fig. 5a, and CVAs at 392 nm, Fig. 5b) are very similar indicating the good reproducibility of the method, even in this complex matrix. The same absorption spectrum at $+0.55 \mathrm{~V}$ in the reverse scan

Table 1 Figures of merit for the linear regression models obtained from the absorbance values at 332 and $392 \mathrm{~nm}$, at $+0.55 \mathrm{~V}$ in the reverse scan

\begin{tabular}{llllll}
\hline $\begin{array}{l}\text { Wave- } \\
\text { length } \\
(\mathrm{nm})\end{array}$ & $\begin{array}{l}\text { Slope } \\
\left(\mu \mathrm{M}^{-1}\right)\end{array}$ & $\begin{array}{l}\text { Intercept } \\
\text { (a.u.) }\end{array}$ & $R^{2}$ & $S_{\mathrm{yx}}$ & $\mathrm{LOD}\left(\mu \mathrm{M}^{-1}\right)$ \\
\hline 332 & $4.7 \cdot 10^{-4}$ & $2.2 \cdot 10^{-3}$ & 0.998 & $7.4 .10^{-4}$ & 4.7 \\
392 & $7.5 \cdot 10^{-4}$ & $2.5 \cdot 10^{-3}$ & 0.998 & $1.2 .10^{-3}$ & 4.8 \\
\hline
\end{tabular}

$R^{2}$ coefficient of determination, $S_{\mathrm{yx}}$ standard deviation of residuals, $L O D$ limit of detection 
Fig. 5 (a) Absorption spectra recorded at different potentials during the oxidation of the Yodocefol® sample. Inset shows the spectra of two Yodocefol ${ }^{\circledR}$ samples at $+0.55 \mathrm{~V}$ in the reverse scan. (b) CVAs at $392 \mathrm{~nm}$ for two Yodocefol ${ }^{\circledR}$ samples. Experimental conditions in the Fig. 2 caption. Optical path length $=2.9 \mathrm{~mm}$

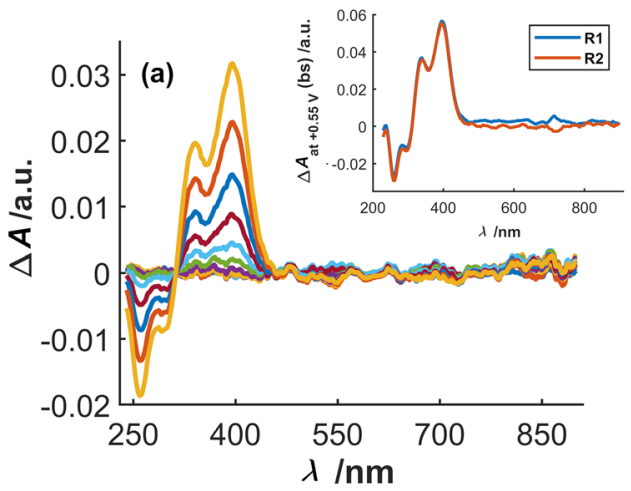

is obtained for the Yodocefol ${ }^{\circledR}$ sample and for a standard solution, as well as the same CVAs at $392 \mathrm{~nm}$ independently on the sample matrix. These results led us to conclude unequivocally that the only molecule that is oxidized is the FA, which is present in the Yodocefol ${ }^{\circledR}$ sample. The oxidation begins at a potential of $+0.55 \mathrm{~V}$, as in the previous cases, increasing the absorbance, until it reaches a maximum absorbance value at $+0.55 \mathrm{~V}$ in the reverse scan, the potential selected for quantification (Fig. 5b).

A concentration of $37 \pm 4 \mu \mathrm{M}$ for the linear regression model obtained with $\Delta \mathrm{A}$ values at $+0.55 \mathrm{~V}$ in reverse scan at $332 \mathrm{~nm}$ and $38 \pm 5 \mu \mathrm{M}$ for the corresponding calibration at $392 \mathrm{~nm}$ was obtained, with the real concentration being $36 \mu \mathrm{M}$. Therefore, a good prediction of the test sample is obtained. Moreover, a low \%RSD, 4.8\%, was assessed for the regression models at the two characteristic wavelengths, which indicates a high degree of coincidence between repeated determinations.

From these results, we can conclude that the new analytical method based on UV/Vis-SEC allows us the determination of FA in complex matrices with very good figures of merit.

\section{Conclusions}

UV/Vis-SEC has been demonstrated to provide very good analytical figures of merit for the determination of FA. It should be noted that electrochemistry is used to generate the oxidation product that, combined with spectroscopy, allows us to obtain a determination of this molecule. In many cases, a double determination of the sample is possible, but sometimes, as in the system shown in this work, the electrochemical signal cannot be used for quantitative purposes, and the determination is made only with the spectroscopic data generated during the oxidation process of the FA. Therefore, the marriage of optical techniques with electrochemistry facilitates the development of analytical methods. It is noteworthy that, in the determination of FA, UV/Vis spectroscopy is used to detect the products of a reaction that are not observed in the electrochemical signal. FA contained in Yodocefol ${ }^{\circledR}$ has been successfully determined. The interfering compounds in this commercial drug do not affect the quantification process, demonstrating the capability of these techniques in the analysis of complex samples. UV/Vis-SEC shows a very good reproducibility, which is remarkable considering the simple pretreatment of the sample prior to its quantification. Moreover, some non-soluble excipient compounds were observed in the test sample, but despite that, highquality analytical figures of merit were obtained. A simple univariate calibration has been used for the determination of test samples, but as has been demonstrated, different absorption bands can be used to carry out the quantification of the sample. Therefore, analytical solutions based on multivariate analysis could be easily implemented to extract the analytical information in case of strong interferences. Additionally, UV/Vis-SEC provides information on the electrochemical oxidation process, allowing to obtain spectra related to the products of the reaction.

Authors' contributions F.O. and A.R. contributed to the acquisition of data. F.O., A.R., A.H, and A.C. contributed to the conception, design, and implementation of the experiments and to the analysis and interpretation of the results. A.H and A.C. contributed to the writing of the manuscript. F.O., A.R., A.H, and A.C. contributed to the revision of the manuscript. This work has been headed by A.H. and A.C.

Funding Open Access funding provided thanks to the CRUE-CSIC agreement with Springer Nature. Authors acknowledge the financial support from Ministerio de Economía y Competitividad (Grant CTQ2017-83935-R-AEI/FEDERUE), Junta de Castilla y León (Grant BU297P18), and Ministerio de Ciencia, Innovación y Universidades (Grant RED2018-102412-T). F.O. is grateful for the contract funded by Junta de Castilla y León, the European Social Fund, and the Youth Employment Initiative.

Data availability Not applicable.

Code availability Not applicable.

\section{Declarations}

Competing interests The authors declare no competing interests. 
Open Access This article is licensed under a Creative Commons Attribution 4.0 International License, which permits use, sharing, adaptation, distribution and reproduction in any medium or format, as long as you give appropriate credit to the original author(s) and the source, provide a link to the Creative Commons licence, and indicate if changes were made. The images or other third party material in this article are included in the article's Creative Commons licence, unless indicated otherwise in a credit line to the material. If material is not included in the article's Creative Commons licence and your intended use is not permitted by statutory regulation or exceeds the permitted use, you will need to obtain permission directly from the copyright holder. To view a copy of this licence, visit http://creativecommons.org/licenses/by/4.0/.

\section{References}

1. Garoz-Ruiz J, Heras A, Colina A (2017) Direct determination of ascorbic acid in a grapefruit: paving the way for in vivo spectroelectrochemistry. Anal Chem 89:1815-1822. https://doi.org/10. 1021/acs.analchem.6b04155

2. Garoz-Ruiz J, Guillen-Posteguillo C, Colina A, Heras A (2019) Application of spectroelectroanalysis for the quantitative determination of mixtures of compounds with highly overlapping signals. Talanta 195:815-821. https://doi.org/10.1016/j.talanta.2018.12.002

3. Paramo AE, Palmero S, Heras A et al (2016) Development of disposable carbon nanofibers electrodes supported on filters. Electroanalysis 28:890-897. https://doi.org/10.1002/elan.201500576

4. Olmo F, Garoz-Ruiz J, Colina A, Heras A (2020) Derivative UV/ Vis spectroelectrochemistry in a thin-layer regime: deconvolution and simultaneous quantification of ascorbic acid, dopamine and uric acid. Anal Bioanal Chem 412:6329-6339. https://doi.org/10. 1007/s00216-020-02564-1

5. Olmo F, Garoz-Ruiz J, Carazo J et al (2020) Spectroelectrochemical determination of isoprenaline in a pharmaceutical sample. Sensors 20:5179. https://doi.org/10.3390/s20185179

6. Garoz-Ruiz J, Perales-Rondon JV, Heras A, Colina A (2019) Spectroelectrochemistry of quantum dots. Isr J Chem 59:679-694. https://doi.org/10.1002/ijch.201900028

7. Scherson DA, Tolmachev YV, Stefan IC (2006) Ultraviolet/visible spectroelectrochemistry. In: Meyers RA (ed) Encyclopedia of Analytical Chemistry. John Wiley \& Sons, Ltd, Chichester, UK, pp 1-54

8. Keyes TE, Forster RJ (2007) Spectroelectrochemistry. In: Zoski CG (ed) Handbook of Electrochemistry. Elsevier B.V., pp 591-635

9. Zhai Y, Zhu Z, Zhou S et al (2018) Recent advances in spectroelectrochemistry Nanoscale 10:3089-3111. https://doi.org/10. 1039/C7NR07803J

10. León L, Mozo JD (2018) Designing spectroelectrochemical cells: a review. TrAC Trends Anal Chem 102:147-169. https://doi.org/ 10.1016/j.trac.2018.02.002

11. Frantz S, Sieger M, Hartenbach I et al (2009) Structure, electrochemistry, spectroscopy, and magnetic resonance, including high-field EPR, of $\{(\mu \text {-abpy })[\operatorname{Re}(\mathrm{CO}) 3 \mathrm{X}] 2\}_{0} / \bullet-$, where abpy $=2,2^{\prime}$-azobispyridine and $\mathrm{X}=\mathrm{F}, \mathrm{Cl}, \mathrm{Br}$, I. J Organomet Chem 694:1122-1133. https://doi.org/10.1016/j.jorganchem.2008.09. 034

12. Garoz-Ruiz J, Perales-Rondon JV, Heras A, Colina A (2019) Spectroelectrochemical sensing: current trends and challenges. Electroanalysis 31:1254-1278. https://doi.org/10.1002/elan.201900075

13. Crayston JA (2003) Spectroelectrochemistry. In: McCleverty JA, Meyer TJ (eds) Comprehensive Coordination Chemistry II. Elsevier, pp 775-789

14. Heras A, Colina A, Ruiz V, López-Palacios J (2003) UV-visible spectroelectrochemical detection of side-reactions in the hexacyanoferrate(III)/
(II) electrode process. Electroanalysis 15:702-708. https://doi.org/10. 1002/elan.200390088

15. Fernández-Blanco C, Colina A, Heras A (2013) UV/Vis spectroelectrochemistry as a tool for monitoring the fabrication of sensors based on silver nanoparticle modified electrodes. Sensors (Basel) 13:5700-5711. https://doi.org/10.3390/s130505700

16. Gonzalez-Baro AC, Izquierdo D, Heras A, Colina A (2020) UV/ Vis spectroelectrochemistry of o-vanillin: study of the antioxidant properties. J Electroanal Chem 859:113844. https://doi.org/ 10.1016/j.jelechem.2020.113844

17. Ventosa E, Colina A, Heras A et al (2012) One-pot synthesis of gold/poly(3,4-ethylendioxythiophene) nanocomposite. J Nanoparticle Res 14:661. https://doi.org/10.1007/s11051-011-0661-z

18. Zanardi C, Terzi F, Pigani L et al (2008) Development and characterisation of a novel composite electrode material consisting of poly(3,4-ethylenedioxythiophene) including Au nanoparticles. Electrochim Acta 53:3916-3923. https://doi.org/10.1016/j. electacta.2007.07.057

19. Di Marino M, Marassi R, Santucci R et al (1987) A spectroelectrochemical study of carboxymethylated cytochrome-c. Bioelectrochemistry Bioenerg 17:27-34. https://doi.org/10.1016/ 0302-4598(87)80004-1

20. Kulesza PJ, Zamponi S, Malik MA et al (1997) Spectroelectrochemical identity of Prussian blue films in various electrolytes: comparison of time-derivative voltabsorptometric responses with conventional cyclic voltammetry. J Solid State Electrochem 1:88-93. https://doi.org/10.1007/s100080050027

21. Kulesza PJ, Zamponi S, Malik MA et al (1998) Spectroelectrochemical characterization of cobalt hexacyanoferrate films in potassium salt electrolyte. Electrochim Acta 43:919-923. https://doi.org/10.1016/S0013-4686(97)00212-0

22. Kulesza PJ, Miecznikowski K, Chojak M et al (2001) Electrochromic features of hybrid films composed of polyaniline and metal hexacyanoferrate. Electrochim Acta 46:4371-4378. https://doi.org/10.1016/S0013-4686(01)00681-8

23. Tesařová E, Heras A, Colina Á et al (2008) A spectroelectrochemical approach to the electrodeposition of bismuth film electrodes and their use in stripping analysis. Anal Chim Acta 608:140-146. https://doi.org/10.1016/j.aca.2007.12.023

24. Noyhouzer T, Snowden ME, Tefashe UM, Mauzeroll J (2017) Modular flow-through platform for spectroelectrochemical analysis. Anal Chem 89:5246-5253. https://doi.org/10.1021/ acs.analchem.6b04649

25. Chen W, Liu X-Y, Qian C et al (2015) An UV-vis spectroelectrochemical approach for rapid detection of phenazines and exploration of their redox characteristics. Biosens Bioelectron 64:25-29. https://doi.org/10.1016/j.bios.2014.08.032

26. León L, Maraver JJ, Carbajo J, Mozo JD (2013) Simple and multi-configurational flow-cell detector for UV-vis spectroelectrochemical measurements in commercial instruments. Sensors Actuators B Chem 186:263-269. https://doi.org/10.1016/j.snb. 2013.06.024

27. Garoz-Ruiz J, Guillen-Posteguillo C, Heras A, Colina A (2018) Simplifying the assessment of parameters of electron-transfer reactions by using easy-to-use thin-layer spectroelectrochemistry devices. Electrochem commun 86:12-16. https://doi.org/10. 1016/j.elecom.2017.11.001

28. Gonzalez-Dieguez N, Colina A, Lopez-Palacios J, Heras A (2012) Spectroelectrochemistry at screen-printed electrodes: determination of dopamine. Anal Chem 84:9146-9153

29. Ghoorchian A, Afkhami A, Madrakian T et al (2020) Absorbancebased spectroelectrochemical sensor for determination of ampyra based on electrochemical preconcentration. Sensors Actuators B Chem 324:128723. https://doi.org/10.1016/j.snb.2020.128723

30. Ball GFM (1994) Water-soluble vitamin assays in human nutrition. Springer, US, Boston, MA 
31. Reynolds E (2006) Vitamin B12, folic acid, and the nervous system. Lancet Neurol 5:949-960. https://doi.org/10.1016/S14744422(06)70598-1

32. Donnelly JG (2001) Folic acid. Crit Rev Clin Lab Sci 38:183-223. https://doi.org/10.1080/20014091084209

33. Reynolds EH (2014) The neurology of folic acid deficiency. In: Biller J, Ferro JM (eds) Handbook of Clinical Neurology, 1st ed. Elsevier B.V., pp 927-943

34. Basu P, Burgmayer SJN (2011) Pterin chemistry and its relationship to the molybdenum cofactor. Coord Chem Rev 255:10161038. https://doi.org/10.1016/j.ccr.2011.02.010

35. O'Neil MJ (2001) The Merck index: an encyclopedia of chemicals, drugs, and biologicals, 13th ed. Whitehouse Station, Merck Manuals, New York, NY

36. Baibarac M, Smaranda I, Nila A, Serbschi C (2019) Optical properties of folic acid in phosphate buffer solutions: the influence of $\mathrm{pH}$ and UV irradiation on the UV-VIS absorption spectra and photoluminescence. Sci Rep 9:14278. https://doi.org/10.1038/ s41598-019-50721-z

37. Gazzali AM, Lobry M, Colombeau L et al (2016) Stability of folic acid under several parameters. Eur J Pharm Sci 93:419-430. https://doi.org/10.1016/j.ejps.2016.08.045

38. D'Souza OJ, Mascarenhas RJ, Satpati AK et al (2017) High electrocatalytic oxidation of folic acid at carbon paste electrode bulk modified with iron nanoparticle-decorated multiwalled carbon nanotubes and its application in food and pharmaceutical analysis. Ionics (Kiel) 23:201-212. https://doi.org/10.1007/ s11581-016-1806-y

39. Akbar S, Anwar A, Kanwal Q (2016) Electrochemical determination of folic acid: a short review. Anal Biochem 510:98-105. https://doi.org/10.1016/j.ab.2016.07.002

40. Kretzschmar K, Jaenicke W (1971) Der Redoxmechanismus des Systems Folsäure-Dihydrofolsäure- Tetrahydrofolsäure II / The Redox Mechanism of the System Folic Acid - Dihydrofolic AcidTetrahydrofolic Acid II. Zeitschrift für Naturforsch B 26:999-1002. https://doi.org/10.1515/znb-1971-1008

41. Ramírez-Herrera DE, Reyes-Cruzaley AP, Dominguez G et al (2019) CdTe quantum dots modified with cysteamine: a new efficient nanosensor for the determination of folic acid. Sensors 19:4548. https://doi.org/10.3390/s19204548

42. Castro RC, Ribeiro DSM, Páscoa RNMJ et al (2020) Dual-emission CdTe/AgInS2 photoluminescence probe coupled to neural network data processing for the simultaneous determination of folic acid and iron (II). Anal Chim Acta 1114:29-41. https://doi.org/10.1016/j. aca.2020.04.007

43. Azizi SN, Shakeri P, Chaichi MJ et al (2014) The use of imidazolium ionic liquid/copper complex as novel and green catalyst for chemiluminescent detection of folic acid by Mn-doped $\mathrm{ZnS}$ nanocrystals. Spectrochim Acta Part A Mol Biomol Spectrosc 122:482-488. https://doi.org/10.1016/j.saa.2013.11.036

44. Matias R, Ribeiro PRS, Sarraguça MC, Lopes JA (2014) A UV spectrophotometric method for the determination of folic acid in pharmaceutical tablets and dissolution tests. Anal Methods 6:3065-3071. https://doi.org/10.1039/c3ay41874j

45. Nagaraja P, Vasantha RA, Yathirajan HS (2002) Spectrophotometric determination of folic acid in pharmaceutical preparations by coupling reactions with iminodibenzyl or 3-aminophenol or sodium molybdate-pyrocatechol. Anal Biochem 307:316-321. https://doi.org/10.1016/S0003-2697(02)00038-6
46. Abo El-Maali N (1992) Carbon paste electrodes modified with palmitic acid and stearic acid for the determination of folic acid (vitamin B9) in both aqueous and biological media. Bioelectrochemistry Bioenerg 342:465-473. https://doi.org/10.1016/00220728(92)85139-T

47. Vaze VD, Srivastava AK (2007) Electrochemical behavior of folic acid at calixarene based chemically modified electrodes and its determination by adsorptive stripping voltammetry. Electrochim Acta 53:1713-1721. https://doi.org/10.1016/j.electacta.2007.08. 017

48. O'Shea TJ, Garcia AC, Blanco PT, Smyth MR (1991) Electrochemical pretreatment of carbon fibre microelectrodes for the determination of folic acid. J Electroanal Chem Interfacial Electrochem 307:63-71. https://doi.org/10.1016/0022-0728(91) 85539-2

49. Gonçalves de Araújo E, Fernandes NS, da Silva Solon LG et al (2015) Voltammetric determination of folic acid using a graphite paste electrode. Electroanalysis 27:398-405. https://doi.org/10. 1002/elan.201400475

50. Chen Z, Chen B, Yao S (2006) High-performance liquid chromatography/electrospray ionization-mass spectrometry for simultaneous determination of taurine and 10 water-soluble vitamins in multivitamin tablets. Anal Chim Acta 569:169-175. https://doi. org/10.1016/j.aca.2006.03.099

51. Brusač J, Klarić A et al (2019) Pharmacokinetic profiling and simultaneous determination of thiopurine immunosuppressants and folic acid by chromatographic methods. Molecules 24:3469. https://doi.org/10.3390/molecules24193469

52. Nelson BC, Sharpless KE, Sander LC (2006) Quantitative determination of folic acid in multivitamin/multielement tablets using liquid chromatography/tandem mass spectrometry. J Chromatogr A 1135:203-211. https://doi.org/10.1016/j.chroma.2006.09.040

53. Gill BD, Saldo S, Wood JE, Indyk HE (2018) A rapid method for the determination of biotin and folic acid in liquid milk, milk powders, infant formula, and milk-based nutritional products by liquid chromatography-tandem mass spectrometry. J AOAC Int 101:1578-1583. https://doi.org/10.5740/jaoacint.18-0065

54. Szakács Z, Noszál B (2006) Determination of dissociation constants of folic acid, methotrexate, and other photolabile pteridines by pressure-assisted capillary electrophoresis. Electrophoresis 27:3399-3409. https://doi.org/10.1002/elps.200600128

55. Thomas AH, Suárez G, Cabrerizo FM et al (2002) Photochemical behavior of folic acid in alkaline aqueous solutions and evolution of its photoproducts. Helv Chim Acta 85:2300-2315. https://doi. org/10.1002/1522-2675(200208)85:8\%3c2300::AID-HLCA2300\% 3e3.0.CO;2-B

56. Chakraborty P, Bairi P, Roy B, Nandi AK (2014) Improved mechanical and electronic properties of co-assembled folic acid gel with aniline and polyaniline. ACS Appl Mater Interfaces 6:3615-3622. https://doi.org/10.1021/am405868j

57. Thomas A, Einschlag FG, Féliz MR, Capparelli AL (1998) First steps in the photochemistry of folate in alkaline medium. J Photochem Photobiol A Chem 116:187-190. https://doi.org/10.1016/ S1010-6030(98)00304-9

58. Thomas AH, Lorente C, Capparelli AL et al (2002) Fluorescence of pterin, 6-formylpterin, 6-carboxypterin and folic acid in aqueous solution: pH effects. Photochem Photobiol Sci 1:421-426. https://doi.org/10.1039/b202114e 